\title{
Regulatory Gap Analysis of Select NUREG-0800 Chapters for Applicability to Molten Salt Reactors
}

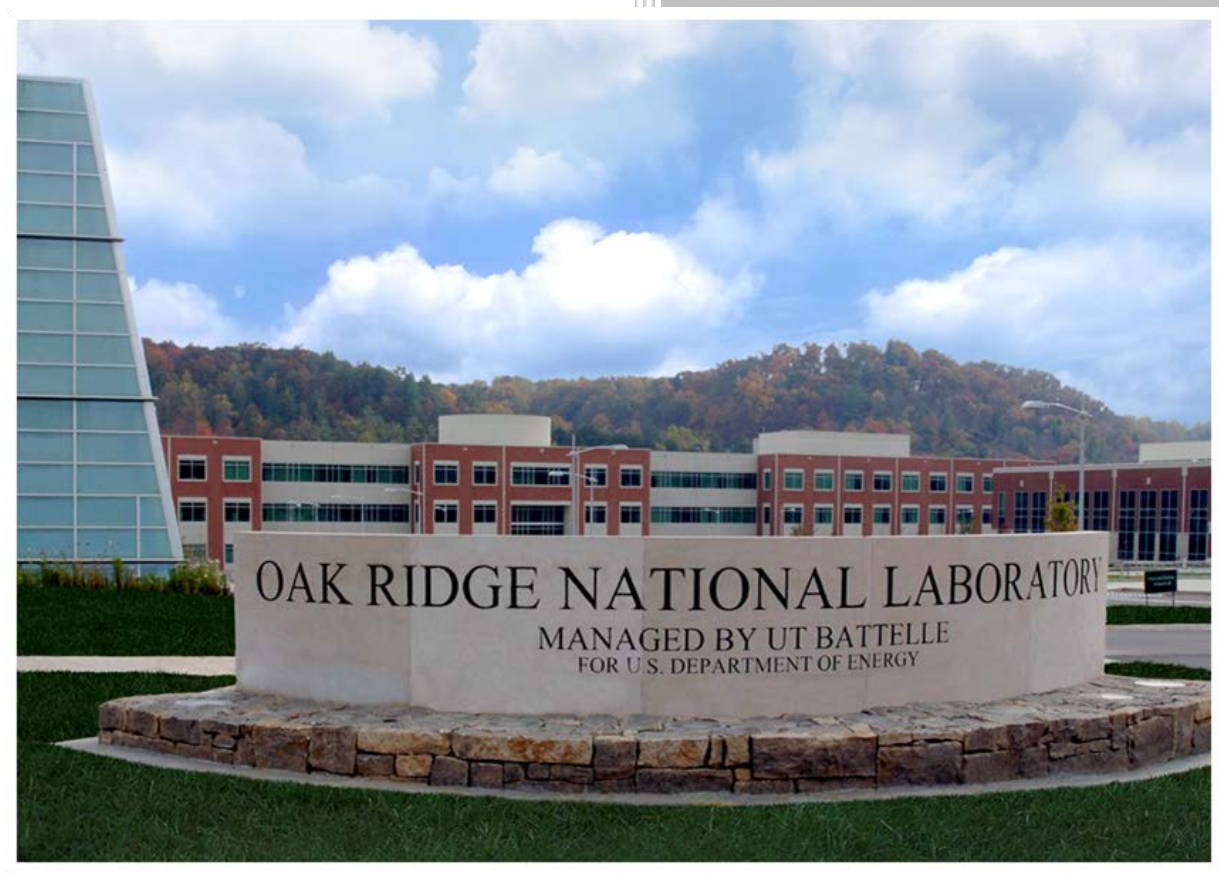
R. J. Belles
G. F. Flanagan

Approved for public release. Distribution is unlimited.

October 2018 


\section{DOCUMENT AVAILABILITY}

Reports produced after January 1, 1996, are generally available free via US Department of Energy (DOE) SciTech Connect.

Website www.osti.gov

Reports produced before January 1, 1996, may be purchased by members of the public from the following source:

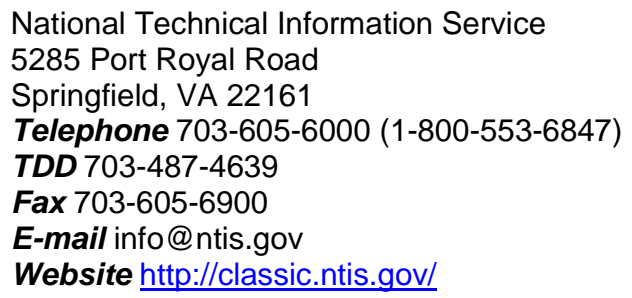

Reports are available to DOE employees, DOE contractors, Energy Technology Data Exchange representatives, and International Nuclear Information System representatives from the following source:

Office of Scientific and Technical Information

PO Box 62

Oak Ridge, TN 37831

Telephone 865-576-8401

Fax 865-576-5728

E-mail reports@osti.gov

Website http://www.osti.gov/contact.html

This report was prepared as an account of work sponsored by an agency of the United States Government. Neither the United States Government nor any agency thereof, nor any of their employees, makes any warranty, express or implied, or assumes any legal liability or responsibility for the accuracy, completeness, or usefulness of any information, apparatus, product, or process disclosed, or represents that its use would not infringe privately owned rights. Reference herein to any specific commercial product, process, or service by trade name, trademark, manufacturer, or otherwise, does not necessarily constitute or imply its endorsement, recommendation, or favoring by the United States Government or any agency thereof. The views and opinions of authors expressed herein do not necessarily state or reflect those of the United States Government or any agency thereof. 
Reactor and Nuclear Systems Division

\title{
REGULATORY GAP ANALYSIS OF SELECT NUREG-0800 CHAPTERS FOR APPLICABILITY TO MOLTEN SALT REACTORS
}

\author{
Randy J. Belles \\ George F. Flanagan
}

Date: October 2018

Prepared by

OAK RIDGE NATIONAL LABORATORY

Oak Ridge, TN 37831-6283

managed by

UT-BATTELLE, LLC

for the

US DEPARTMENT OF ENERGY

under contract DE-AC05-00OR22725 



\section{CONTENTS}

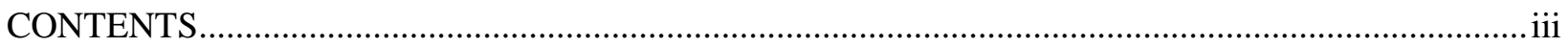

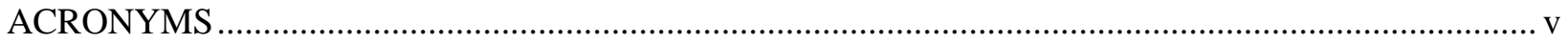

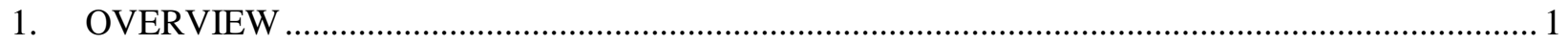

2. DESCRIPTION OF WORK

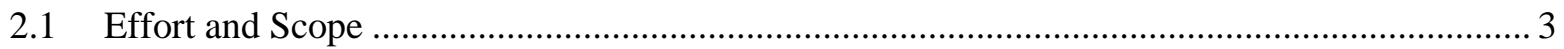

3. OBSERVATIONS ON SIGNIFICANT NUREG-0800 REVIEW RESULTS ................................ 9

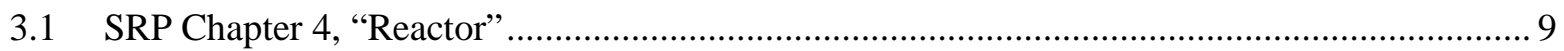

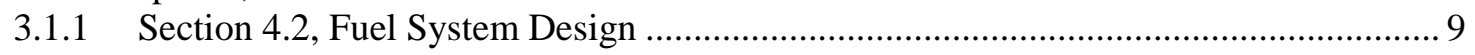

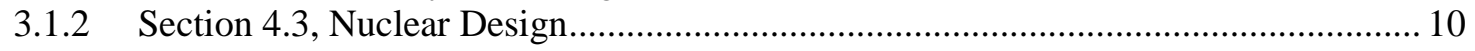

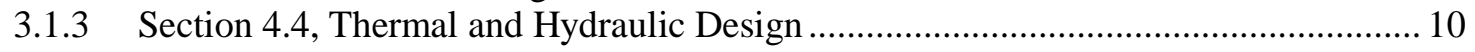

3.1.4 Section 4.5.1, Control Rod Drive and Structural Materials .......................................... 11

3.1.5 Section 4.5.2, Reactor Internal and Core Support Structure Materials ........................ 11

3.1.6 Section 4.6, Functional Design of Control Rod Drive System .................................... 11

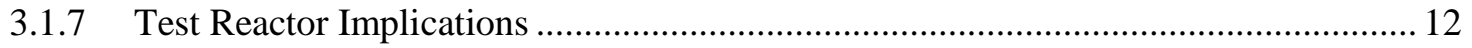

3.2 SRP Chapter 5, "Reactor Coolant System and Connected Systems" ..................................... 13

3.2.1 Section 5.2, Reactor Coolant Pressure Boundary ……................................................ 13

3.2.2 Section 5.3, Reactor Vessel ................................................................................ 14

3.2.3 Section 5.4, Reactor Coolant System Component and Subsystem Design.................. 15

3.2.4 Section 5.5, MSR Coolant Loop Component and Subsystem Design (New) ............... 15

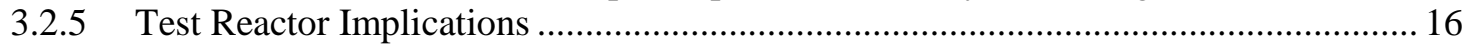

3.3 SRP Chapter 6, "Engineered Safety Features” ....................................................................... 17

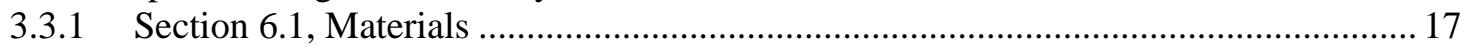

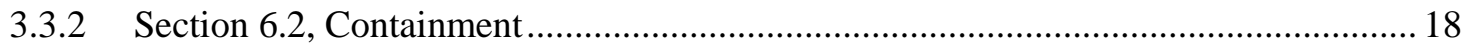

3.3.3 Section 6.3, Emergency Core Cooling System ...................................................... 19

3.3.4 Section 6.4, Control Room Habitability System...................................................... 19

3.3.5 Section 6.5, Containment Support Systems ............................................................. 19

3.3.6 Section 6.6, Inservice Inspection and Testing of Class 2 and 3 Components.............. 20

3.3.7 Section 6.7, Main Steam Isolation Valve Leakage Control System (BWR)................ 20

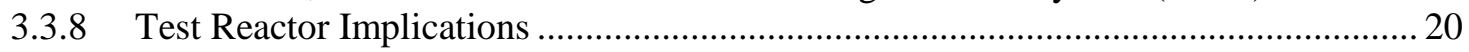

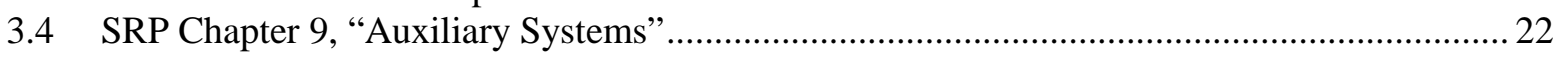

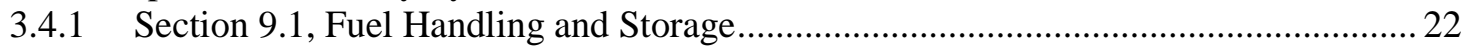

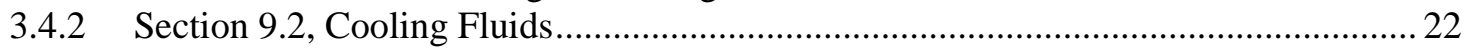

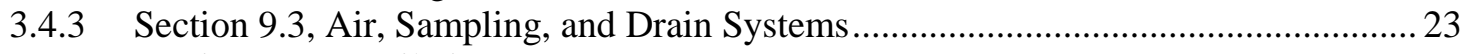

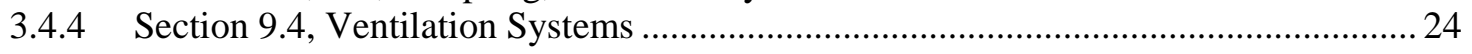

3.4.5 Section 9.5, Fire, Communications, Lighting, and Diesel Support Systems ............... 25

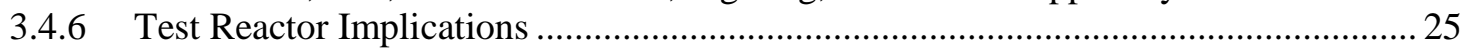

3.5 SRP Chapter 11, "Radioactive Waste Management” .......................................................... 27

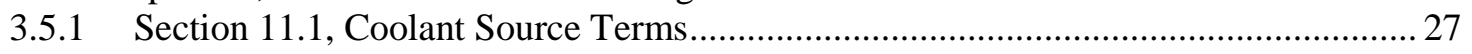

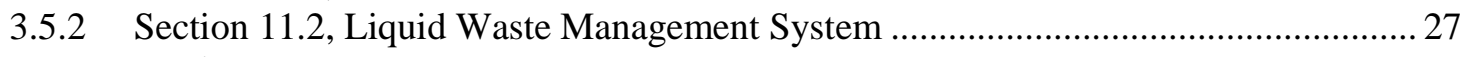

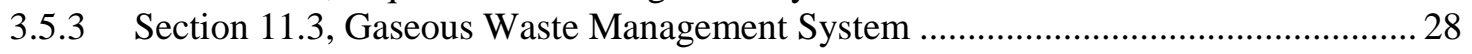

3.5.4 Section 11.4, Solid Waste Management System....................................................... 28

3.5.5 Section 11.5, Process and Effluent Radiological Monitoring Instrumentation and

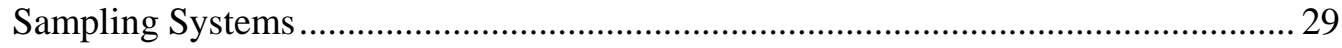

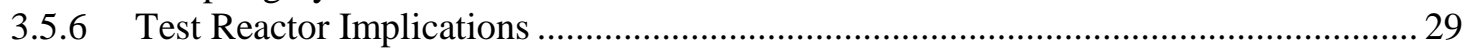

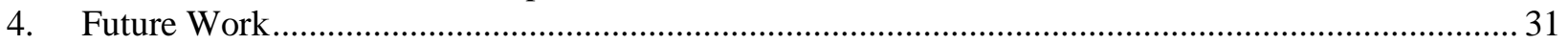





\section{ACRONYMS}

$\begin{array}{ll}\text { AOO } & \text { anticipated operational occurrences } \\ \text { ASME } & \text { American Society of Mechanical Engineers } \\ \text { BWR } & \text { boiling water reactor } \\ \text { CFR } & \text { Code of Federal Regulations } \\ \text { CRDM } & \text { control rod drive mechanism } \\ \text { CSF } & \text { condensate storage facility } \\ \text { DOE } & \text { US Department of Energy } \\ \text { DOE-NE } & \text { US Department of Energy, Office of Nuclear Energy } \\ \text { ECCS } & \text { emergency core cooling system } \\ \text { ESF } & \text { engineered safety features } \\ \text { FPP } & \text { fire protection program } \\ \text { GWMS } & \text { gaseous waste management system } \\ \text { ISI } & \text { in-service inspection } \\ \text { LBE } & \text { licensing basis event } \\ \text { LOCA } & \text { loss-of-coolant accident } \\ \text { LWMS } & \text { liquid waste management system } \\ \text { LWR } & \text { light water reactor } \\ \text { MSR } & \text { molten salt reactor } \\ \text { NFPA } & \text { National Fire Protection Association } \\ \text { NRC } & \text { US Nuclear Regulatory Commission } \\ \text { ORNL } & \text { Oak Ridge National Laboratory } \\ \text { PERMISS } & \text { process and effluent radiological monitoring instrumentation and sampling } \\ \text { P-T } & \text { system } \\ \text { PTS } & \text { pressure-temperature } \\ \text { PWR } & \text { pressurized thermal shock } \\ \text { QA } & \text { pressurized water reactor } \\ \text { RCPB } & \text { quality assurance } \\ \text { RCS } & \text { reactor coolant pressure boundary } \\ \text { RG } & \text { reactor coolant system } \\ \text { RHR } & \text { Regulatory Guide } \\ \text { SAFDL } & \text { residual heat removal } \\ \text { SAR } & \text { specified acceptable fuel design limits } \\ \text { SRP } & \text { safety analysis report } \\ \text { SSC } & \text { Standard Review Plan (NUREG-0800) } \\ \text { SWMS } & \text { structure, system, and component } \\ \text { USE } & \text { solid waste management system } \\ & \text { upper-shelf energy } \\ & \end{array}$





\section{OVERVIEW}

Molten salt reactors (MSRs), both inherently and through good design, possess highly desirable safety attributes. Successful commercial deployment of liquid-fueled MSRs is heavily dependent on reflecting their safety characteristics in a well-coordinated licensing requirements program.

The past licensing approach for advanced reactors was based on adapting the current light water reactor (LWR)-based US Nuclear Regulatory Commission (NRC) process that exists today to the advanced reactor concept. This is the approach used by advanced technologies such as the Pebble Bed Reactor licensing application, the Clinch River Breeder Reactor licensing application, and more recently the NuScale licensing application.

NRC has recognized some of the unique passively safe aspects of advanced non-LWR reactors and has introduced an advanced reactor strategic plan that will address the policy issues needed to accommodate advanced reactor concepts within the existing regulatory framework. Examples of some of these policy issues are use of functional containment, use of mechanistic source terms, more reliance on performancebased and risk-informed regulatory processes to select licensing basis events (LBEs), safety categorization of structures, systems, and components (SSCs), and well-defined defense-in-depth systems. Applying performance-based, risk-informed regulatory processes is, consequently, vital to substantially decreasing the cost, time, and uncertainty of commercial MSR reactor licensing while providing for the health and safety of the public and protecting the environment.

A Department of Energy (DOE) Office of Nuclear Energy (NE) initiative is underway to support the research, development, and demonstration of advanced (non-LWR) reactor technologies. MSRs represent one of the advanced non-LWR technologies selected by DOE for development through a multiyear cost share award with Southern Company. Current Standard Review Plan (SRP) guidance for large LWRs is available in NUREG-0800, Standard Review Plan for the Review of Safety Analysis Reports for Nuclear Power Plants: Light Water Reactor (LWR) Edition. However, the SRP is cumbersome to apply to liquidfueled MSR technologies. Therefore, a thoughtful licensing approach for MSRs is necessary.

DOE-NE previously supported a regulatory gap analysis of ${ }^{1}$ and proposed update to ${ }^{2}$ NUREG-1537, Guidelines for Preparing and Reviewing Applications for the Licensing of Non-Power Reactors, for their applicability to nonpower MSRs operating with a homogeneous fuel salt mixture. These nonpower MSR test facilities can provide much of the performance data needed for review of commercial-sized MSR technology by NRC staff. Chapters included in the NUREG-1537 analysis are listed here.

- Chapter 4, "Reactor Description”

- Chapter 5, "Reactor Coolant Systems”

- Chapter 6, "Engineered Safety Features”

- Chapter 9, “Auxiliary Systems”

- Chapter 11, "Radiation Protection Program and Waste Management”

The analysis was conducted by staff members from Oak Ridge National Laboratory (ORNL) with support from Boston Government Services, LLC. The NUREG-1537 chapters listed above were selected for review because of expected differences in addressing advanced non-LWR technologies, specifically nonpower MSRs, compared with water-based nonpower reactors. Except for Chapter 13, “Accident

\footnotetext{
${ }^{1}$ Belles, R. J., G. F. Flanagan, and M. Voth. 2016. Regulatory Gap Analysis of Guidelines for Preparing and Reviewing Applications for the Licensing of Non-Power Reactors (NUREG-1537) for Applicability to Molten Salt Reactors. ORNL/SR2016/725, December. Oak Ridge, TN: Oak Ridge National Laboratory.

${ }^{2}$ Belles, R. J., G. F. Flanagan, and M. Voth. 2018. Proposed Guidance for Preparing and Reviewing Molten Salt Nonpower Reactor License Applications (NUREG-1537). ORNL/TM-2018/834, May. Oak Ridge, TN: Oak Ridge National Laboratory.
} 
Analyses," the remaining NUREG-1537 chapters were not expected to differ significantly in their applicability to an MSR design relative to current nonpower reactors and were not reviewed. Chapter 13 requires a design-specific analysis that is dependent on the appropriate selection of LBEs.

This report documents for DOE-NE an additional regulatory gap analysis of select chapters from the LWR SRP to further inform a generic nonpower MSR test program. Although the review process outlined in NUREG-0800 is LWR-specific, the plant functions and processes to be reviewed will be similar for the MSR. Therefore, a well-planned nonpower MSR test program can provide the performance data needed to better facilitate the eventual commercial-sized MSR review. As with the NUREG-1537 review, the LWR SRP chapters dealing with the reactor, reactor coolant, engineered safety features, auxiliary systems, and waste management systems were reviewed:

- Chapter 4, "Reactor"

- Chapter 5, "Reactor Coolant System and Connected Systems"

- Chapter 6, "Engineered Safety Features”

- Chapter 9, “Auxiliary Systems”

- Chapter 11, "Radioactive Waste Management”

Except for Chapter 15, "Transient and Accident Analysis," the remaining LWR SRP chapters were not expected to differ significantly regarding their applicability to an MSR design relative to current LWRs and were not reviewed. Chapter 15 requires a design-specific analysis that is dependent on the appropriate selection of LBEs.

Section 2 of this report describes the structured process that guided the review of NUREG-0800.

Section 3 presents an overview of the results. The gap analysis of each SRP chapter was thoroughly documented on an Excel spreadsheet. The spreadsheets were provided individually to the sponsor and are available on request. The spreadsheets are not reproduced in this report. 


\section{DESCRIPTION OF WORK}

The NUREG-0800 sections included in this report were evaluated relative to (1) regulatory gap analysis of NUREG-1537³, (2) the proposed update to NUREG-15374, and (3) a generic working knowledge of MSRs operating with homogenous fuel based on documentation of Molten Salt Reactor Experiment operation at ORNL. LWRs contain heterogeneous fuel elements consisting of rods, plates, or pins whose cladding acts as the initial fission product barrier. In an MSR, the initial fission product barrier is the fuel salt system boundary and interfacing system boundaries. These elements further impact some of the traditional discussion of fuel and coolant systems, as well as some of the auxiliary systems required.

\subsection{EFFORT AND SCOPE}

ORNL staff reviewed specific chapters of the LWR SRP individually in sequence. Each section within the selected chapters was reviewed to identify perceived SRP regulatory gaps associated with the review of an MSR application. Specifically, each section was reviewed, and evaluations were made on the MSR applicability of listed review areas, acceptance criteria, review procedures, and evaluation findings. The unique characteristics of liquid-fueled MSRs and associated support systems were contrasted with the heterogeneous fuel and cooling characteristics considered by the SRP.

NUREG-0800 Chapter 4, "Reactor," addresses several areas related to reactor design in the following sections:

4.2 “Fuel System Design” (includes discussion of reactor fuel, control rods, and coolability)

4.3 “Nuclear Design” (includes discussion of fuel design limits)

4.4 “Thermal and Hydraulic Design”

4.5.1 “Control Rod Drive Structural Materials”

4.5.2 "Reactor Internal and Core Support Structure Materials”

4.6 "Functional Design of Control Rod Drive System” (confirms that the system can effect a safe shutdown)

BTP 4-1 "Westinghouse Constant Axial Offset Control (CAOC)” (not applicable to MSR technology)

NUREG-0800 Chapter 5, "Reactor Coolant System and Connected Systems," addresses several areas related to reactor coolant, reactor heat removal, and interfacing systems:

5.2.1.1 “Compliance with the Codes and Standards Rule, 10 CFR 50.55a”

5.2.1.2 “Applicable Code Cases”

5.2.2 “Overpressure Protection”

5.2.3 “Reactor Coolant Pressure Boundary Materials”

5.2.4 “Reactor Coolant Pressure Boundary Inservice Inspection and Testing”

5.2.5 “Reactor Coolant Pressure Boundary Leakage Detection”

\footnotetext{
${ }^{3}$ Belles, R. J., G. F. Flanagan, and M. Voth. 2016. Regulatory Gap Analysis of Guidelines for Preparing and Reviewing Applications for the Licensing of Non-Power Reactors (NUREG-1537) for Applicability to Molten Salt Reactors. ORNL/SR2016/725, December. Oak Ridge, TN: Oak Ridge National Laboratory.

${ }^{4}$ Belles, R. J., G. F. Flanagan, and M. Voth. 2018. Proposed Guidance for Preparing and Reviewing Molten Salt Nonpower Reactor License Applications (NUREG-1537). ORNL/TM-2018/834, May. Oak Ridge, TN: Oak Ridge National Laboratory.
} 


\subsection{1 "Reactor Vessel Materials"}

5.3.2 “Pressure-Temperature Limits, Upper-Shelf Energy, and Pressurized Thermal Shock”

5.3.3 "Reactor Vessel Integrity”

5.4 "Reactor Coolant System Component and Subsystem Design”

5.4.1.1 “Pump Flywheel Integrity (PWR)” (not applicable to MSR technology)

5.4.2.1 “Steam Generator Materials and Design”

5.4.2.2 “Steam Generator Program”

5.4.6 “Reactor Core Isolation Cooling System (BWR)” (not applicable to MSR technology)

5.4.7 “Residual Heat Removal (RHR) System”

5.4.8 “Reactor Water Cleanup System (BWR)” (not applicable to MSR technology)

5.4.11 “Pressurizer Relief Tank” (not applicable to MSR technology)

5.4.12 “Reactor Coolant System High Point Vents” (not applicable to MSR technology)

5.4.13 “Isolation Condenser System (BWR)” (not applicable to MSR technology)

5.4.14 “Fuel Salt Pump (MSR)” (proposed new subsection)

5.4.15 “Primary Heat Exchanger (MSR)” (proposed new subsection)

5.4.16 “Gas Management System (MSR)” (proposed new subsection)

5.4.17 “Fuel Salt Cleanup or Polishing System (MSR)” (proposed new subsection)

5.4.18 “Fuel Salt Makeup System (MSR)” (proposed new subsection)

5.4.19 “Fuel Salt Sampling System (MSR)” (proposed new subsection)

5.4.20 “Fuel Salt Drain Tank (MSR)” (proposed new subsection)

5.4.21 “Freeze Valve Boundary (MSR)” (proposed new subsection)

5.4.22 “Intra-connecting piping which might contain fuel salt (MSR)” (proposed new subsection)

BTP 5-1 “Monitoring of Secondary Side Water Chemistry in PWR Steam Generators” (not applicable to MSR technology)

BTP 5-2 “Overpressurization Protection of Pressurized-Water Reactors While Operating at Low Temperatures” (not applicable to MSR technology)

BTP 5-3 “Fracture Toughness Requirements” (not applicable to MSR technology)

BTP 5-4 “Design Requirements of the Residual Heat Removal System” (not applicable to MSR technology)

NUREG-0800 Chapter 6, "Engineered Safety Features,” addresses several areas related to engineered safety features:
6.1.1 "Engineered Safety Features Materials"
6.1.2 "Protective Coating Systems (Paints) - Organic Materials”
6.2.1 “Containment Functional Design” (includes various containment configurations, subcompartment analysis, and mass and energy analyses)
6.2.2 “Containment Heat Removal Systems” 
6.2.3 “Secondary Containment Functional Design”

6.2.4 “Containment Isolation System”

6.2.5 “Combustible Gas Control in Containment”

6.2.6 “Containment Leakage Testing”

6.2.7 "Fracture Prevention of Containment Pressure Boundary"

6.3 "Emergency Core Cooling System"

6.4 “Control Room Habitability System"

6.5.1 “ESF Atmosphere Cleanup Systems”

6.5.2 “Containment Spray as a Fission Product Cleanup System”

6.5.3 "Fission Product Control Systems and Structures"

6.5.4 “Ice Condenser as a Fission Product Cleanup System”

6.5.5 “Pressure Suppression Pool as a Fission Product Cleanup System”

6.6 "Inservice Inspection and Testing of Class 2 and 3 Components”

6.7 "Main Steam Isolation Valve Leakage Control System (BWR)" (not applicable to MSR technology)

BTP 6-1 “pH for Emergency Coolant Water for Pressurized Water Reactors” (not applicable to MSR technology)

BTP 6-2 “Minimum Containment Pressure Model for PWR ECCS Performance Evaluation” (not applicable to MSR technology)

BTP 6-3 “Determination of Bypass Leakage Paths in Dual Containment Plants” (not applicable to MSR technology)

BTP 6-4 “Containment Purging During Normal Plant Operations”

BTP 6-5 "Currently the Responsibility of Reactor Systems Piping from the RWST (or BWST) and Containment Sump(s) to the Safety Injection Pumps” (not applicable to MSR technology)

NUREG-0800 Chapter 9, “Auxiliary Systems,” addresses several areas related to essential auxiliary systems such as fuel handling, cooling systems, ventilation systems, and emergency power:

9.1.1 “Criticality Safety of Fresh and Spent Fuel Storage and Handling”

9.1.2 "New and Spent Fuel Storage"

9.1.3 “Spent Fuel Pool Cooling and Cleanup System”

9.1.4 "Light Load Handling System and Related Refueling Operations”

9.1.5 “Overhead Heavy Load Handling Systems”

9.1.X “Fuel Salt Load Handling System” (proposed new subsection)

9.1.X “Fuel Accountability System” (proposed new subsection)

9.2.1 “Station Service Water System”

9.2.2 “Reactor Auxiliary Cooling Water Systems"

9.2.3 “Demineralized Water Makeup System” 
9.2.4 "Potable and Sanitary Water Systems"

9.2.5 "Ultimate Heat Sink"

9.2.6 “Condensate Storage Facilities”

9.2.7 “Chilled Water”

9.2.X “Reactor Auxiliary Cooling Fluid System” (proposed new subsection for air cooling)

9.2.X "Fuel Salt Storage Cooling Fluid System” (proposed new subsection for irradiated fuel salt sampling or letdown storage)

9.2.X “Gas Management System Cooling”

9.2.X “Fuel Salt Drain Tank Cooling System” (proposed new subsection)

9.2.X “Primary Coolant Drain Tank Cooling System” (proposed new subsection)

9.2.7 “Chilled Water”

9.3.1 “Compressed Air System”

9.3.2 "Process and Post-accident Sampling Systems"

9.3.3 “Equipment and Floor Drainage System”

9.3.4 “Chemical and Volume Control System (PWR)"

9.3.5 "Standby Liquid Control System (BWR)"

9.3.X “MSR Fuel Salt Heating System” (proposed new subsection)

9.3.X “MSR Cover Gas Cleanup and Purification System” (proposed new subsection)

9.4.1 “Control Room Area Ventilation System”

9.4.2 “Spent Fuel Pool Area Ventilation System”

9.4.3 “Auxiliary and Radwaste Area Ventilation System”

9.4.4 “Turbine Area Ventilation System”

9.4.5 "Engineered Safety Feature Ventilation System”

9.4.X “MSR Fuel Salt Storage Ventilation System” (proposed new subsection)

9.5.1.1 “Fire Protection Program”

9.5.1.2 “Risk-Informed (RI), Performance-Based (PB) Fire Protection Program (FPP)”

9.5.2 “Communication Systems”

9.5.3 “Lighting Systems”

9.5.4 “Emergency Diesel Engine Fuel Oil Storage and Transfer System”

9.5.5 “Emergency Diesel Engine Cooling Water System”

9.5.6 “Emergency Diesel Engine Starting System”

9.5.7 “Emergency Diesel Engine Lubrication System”

9.5.8 “Emergency Diesel Engine Combustion Air Intake and Exhaust System” 
NUREG-0800 Chapter 11, "Radioactive Waste Management," addresses liquid, gaseous, and solid waste management:

11.1 “Coolant Source Terms”

11.2 “Liquid Waste Management System”

11.3 “Gaseous Waste Management System”

11.4 “Solid Waste Management System”

11.5 "Process and Effluent Radiological Monitoring Instrumentation and Sampling Systems”

BTP 11-3 “Design Guidance for Solid Radioactive Waste Management Systems Installed in LWRs”

BTP 11-5 “Postulated Radioactive Releases Due to a Waste Gas System Leak or Failure”

BTP 11-6 “Postulated Radioactive Releases Due to Liquid-containing Tank Failures” (not applicable to MSR technology)

These SRP sections were reviewed to identify the broad spectrum of review areas for LWR designs and to assess their applicability and suitability to MSR designs. Not all the reviewed SRP sections are applicable in whole or in part to MSR designs.

The review team developed a Microsoft Excel spreadsheet to guide the reviews in a consistent manner. The spreadsheets were submitted to the sponsor as they were completed. The spreadsheet column headings shown below provided objective information, such as section numbers and titles; subjective information, such as summaries of recommended changes, key technical issues, and bases for changes; and qualitative information, such as the ease or difficulty in implementing each change, new method, or new approach. A key element included in the spreadsheet is an evaluation of any implications of the review areas, acceptance criteria, review procedures, evaluation findings, or references to the performance testing and data needed from the test reactor for review of a commercial-scale reactor. A summary of the spreadsheet structure and review guidance is shown in Table 1.

Identified regulatory gaps in the reviewed NUREG-0800 sections to support licensing a nonpower MSR were based on generic MSR features rather than focusing on a particular design. MSR designs typically include an intermediate coolant loop not found in current LWR designs. As a result, terminology can be very specific for different proposed MSR designs. For example, the terms primary coolant and secondary coolant as used in Chapter 5 can be subject to a variety of terms for specific MSR designs. Therefore, the review attempted to keep MSR terminology as generic as possible in the gap analysis. 
Table 1. Review spreadsheet and guidance

\begin{tabular}{|c|c|c|}
\hline Column & Title & Notes for content of each column \\
\hline A & Document number & Document number or other identifying attributes \\
\hline B & Document title & Document title, section title, memo subject, etc. \\
\hline $\mathrm{C}$ & Referenced in & $\begin{array}{l}\text { For references, note the SRP section and reference number where they } \\
\text { were called out }\end{array}$ \\
\hline $\mathrm{D}$ & Change summary & General summary of the changes that are needed (short, high level) \\
\hline $\mathrm{E}$ & Changes needed & $\begin{array}{l}\text { Number as it applies to each row (1-6). } \\
\text { Change code: } \\
1=\text { no changes needed } \\
2 \text { = limited changes needed (e.g., only change terminology) } \\
3 \text { = substantive changes needed } \\
4 \text { = insufficient design info to know how extensive the changes might be } \\
5=\text { not applicable to the design reviewed } \\
6=\text { new design-specific requirement to add }\end{array}$ \\
\hline $\mathrm{F}$ & Key technical issues & $\begin{array}{l}\text { Summarize what the key technical issues are. If no changes, enter "none" } \\
\text { here }\end{array}$ \\
\hline G & $\begin{array}{l}\text { Test reactor } \\
\text { implications }\end{array}$ & $\begin{array}{l}\text { Are there any test reactor implications to support the prototype safety } \\
\text { analysis report (SAR) development for this section? }\end{array}$ \\
\hline $\mathrm{F}$ & Comments, notes & $\begin{array}{l}\text { Additional thoughts or notes that might clarify discussion. Links to other } \\
\text { line items }\end{array}$ \\
\hline $\mathrm{L}$ & Rationale & Basis for making any changes \\
\hline
\end{tabular}




\section{OBSERVATIONS ON SIGNIFICANT NUREG-0800 REVIEW RESULTS}

MSR technology considered by this report is based on homogenous liquid fuel in a halide salt mixture. The halide salts used have good heat transfer characteristics. Additionally, actinides have been demonstrated to be highly soluble in halide salts, so the fuel becomes part of the cooling system. Liquid fuel is present in the core and outside the core region. Traditional fuel fabrication is eliminated, and excess reactivity, and consequently control rod worth, can be limited because additional fuel can be blended into the fuel salt as needed. Burnup limits are also eliminated as a fuel lifecycle limitation. The fuel salt has a low vapor pressure at operating temperatures, so the fuel salt system boundary is a lowpressure system. In addition, anticipated operational occurrences (AOOs) and accidents that add heat to the system tend to shut down the fission process. The equivalent of the LWR fuel clad essentially becomes the fuel salt system boundary. This combination of fuel and coolant blurs the traditional lines of separation between the fuel and the coolant system found in NUREG-0800 Chapters 4 and 5. In addition, many of the engineered safety features discussed in Chapter 6 do not apply to MSRs. Additional auxiliary systems need to be considered for Chapter 9 due to the unique nature of MSR operations. Finally, waste processing must be reevaluated in Chapter 11 considering the highly radioactive environment created by MSR operations. NUREG-0800 Chapters 4, 5, 6, 9, and 11 were selected for the gap analyses based on the likelihood that these chapters would provide the most regulatory differences between LWRs and MSRs. Subsequently, these chapters should point to many of the test and data needs to be filled by an MSR test reactor.

The SRP review materials are based on over 50 years of experience with commercial LWRs (heterogeneous fuel systems), including the extensive research conducted on topics pertinent to LWRs. The MSR technology does have historical precedence for demonstrating key principles of design and limited years of operating experience; however, the MSR experience is not as comprehensive as it is for LWR technologies. Highlights of the gap reviews for the individual LWR SRP chapters are presented below. Implications for an MSR test reactor are presented at the end of each section of highlights.

\subsection{SRP CHAPTER 4, “REACTOR”}

LWR technology is based on heterogeneous fuel that includes a protective clad for the uranium oxide fuel pellets. Fission products are retained within the fuel rod structure. Therefore, fuel lifecycle is limited by burnup and fission product accumulation within the fuel rods. Chapter 4 provides the review criteria for the fuel, the neutronics, and the thermal-hydraulics in the core. The focus of the NUREG-0800 Chapter 4 review is to (1) provide assurance that the reactor design can maintain core parameters within specified acceptable fuel design limits (SAFDLs) during normal operation and AOOs, and (2) provide assurance that the core can be maintained in a coolable core geometry during accident conditions.

Initial reviews of the LWR SRP sections and subsections associated with Chapters 4 and 5 revealed fundamental differences in the potential suitability of LWR technology applied to the assessment of the reactor components for a liquid-fueled MSR and for the testing and data to be supplied by a nonpower MSR design to meet the LWR SRP review requirements. It is difficult to integrate the current infrastructure of these two chapters with generic MSR technology.

\subsubsection{Section 4.2, Fuel System Design}

The SRP Section 4.2 text indicates that transient and accident analyses should be evaluated on the thermal, mechanical, and materials design of the LWR fuel system. As noted in the text:

The fuel system consists of arrays (assemblies or bundles) of fuel rods, including fuel pellets, insulator pellets, springs, tubular cladding, end closures, hydrogen getters, and fill 
gas; burnable poison rods including components like those in fuel rods; spacer grids and springs; end plates; channel boxes; and reactivity control rods.

In an MSR, there is no mechanical structure for the fuel, so mechanical reviews are unnecessary. The material design focus shifts from structural components of the heterogeneous LWR fuel assembly, including the clad, to a chemical evaluation of the MSR fuel salt.

Section 4.2 indicates that the LWR fuel system safety review provides assurance that (1) the fuel system is not damaged because of normal operation and AOOs, (2) fuel system damage is never so severe as to prevent control rod insertion when it is required, (3) the number of fuel rod failures is not underestimated for postulated accidents, and (4) coolability is always maintained. In an MSR, only point 4 remains an issue for review. The fuel system damage referenced in points 1 and 2 is analogous to fuel salt system boundary damage, which is discussed in SRP Chapter 5.

The Section 4.2 review focuses on SAFDLs to demonstrate that the LWR heterogeneous fuel is not damaged. SAFDLs do not translate to MSR homogeneous fuel. Protection of the MSR fuel becomes a chemistry exercise to maintain the fuel salt within a window defined by specific chemical parameters such as fissile material solubility, viscosity, and heat capacity.

Section 4.2 needs to be retained for a review of MSR fuel, but it needs an extensive rewrite. The focus needs to be on a thermal and chemical analysis of the fuel salt. Note that corrosion at the fuel salt system boundary should be evaluated in a revision to Section 5.2.

\subsubsection{Section 4.3, Nuclear Design}

The Section 4.3 LWR review text indicates:

The review of the nuclear design of the fuel assemblies, control systems, and reactor core is carried out to aid in confirming that fuel design limits will not be exceeded during normal operation or AOOs and that the effects of postulated reactivity accidents will not cause significant damage to the reactor coolant pressure boundary (RCPB) or impair the capability to cool the core.

The SRP review focuses on the core power distribution and reactivity coefficients. It should be demonstrated that limits and setpoints for actions, alarms, or scram for the instrument systems can maintain the reactor within design power distribution limits. Although structural protection of fuel assemblies is not an MSR issue, an evaluation of the reactor control systems and the reactor core is appropriate.

Section 4.3 needs to be retained for a review of MSR fuel, but it needs an extensive rewrite because of the extensive focus on heterogeneous LWR fuel. The focus needs to be on the MSR core and control systems. Note that control rods, control rod patterns, and reactivity worths are discussed extensively in this section. MSRs may use control elements other than control rods and intrinsic nuclear phenomena, such as flow, to provide reactor control.

\subsubsection{Section 4.4, Thermal and Hydraulic Design}

The Section 4.4 LWR review text indicates:

The review should confirm that the thermal and hydraulic design of the core and the reactor coolant system (RCS) (1) uses acceptable analytical methods, (2) is equivalent to or is a justified extrapolation from proven designs, (3) provides acceptable margins of safety from conditions that would lead to fuel damage during normal reactor operation and AOOs, and (4) is not susceptible to thermal-hydraulic instability. 
The reviewer examines core and RCS component features, key process variables for the coolant system, calculated parameters characterizing thermal performance, data serving to support new correlations or changes in accepted correlations, and assumptions in the equations and solution techniques used in the analyses.

For an MSR review, item 2 above will rely heavily on experimental loops and perhaps a test reactor. Fuel damage is not a structural consideration for MSRs, so item 3 is not a consideration since fuel salt chemistry is evaluated in Section 4.2.

Section 4.4 needs to be retained for a review of MSR thermal hydraulics. The focus needs to be on acceptable analytical methods. Note that LWR flow instability measures such as departure form nucleate boiling, critical heat flux, and critical power ratio are not applicable to MSR technology, but other mechanisms may exist, such as gas generation or entrainment.

\subsubsection{Section 4.5.1, Control Rod Drive and Structural Materials}

The Section 4.5.1 LWR review text indicates:

The properties of the control rod drive materials are reviewed for adequate performance throughout the design life of the plant (or component).

For purposes of this SRP section, the control rod system is composed of the control rod drive mechanism (CRDM) and extends only to the coupling interface with the reactivity control (poison) elements in the reactor vessel; it does not include the electrical and hydraulic systems necessary to actuate the CRDMs. It should be noted that MSRs generally consider a variety of control elements rather than control rods, because rods are not the obvious control method for many MSR technologies. Section 4.5.1 is compatible with MSR technology except for terminology and American Society of Mechanical Engineers (ASME) references for high temperature materials.

\subsubsection{Section 4.5.2, Reactor Internal and Core Support Structure Materials}

The Section 4.5.2 LWR review text indicates:

The review should evaluate the adequacy of the materials selected for the construction of the LWR reactor internal and core support structures, as defined in NG-1120 of ASME Boiler and Pressure Vessel Code Section III, and to assure that the reactor internal and core support structures meet these regulations. The reactor internal and core support structures reviewed under this SRP section include all structures and components within the pressure vessel other than the fuel and control assemblies, and instrumentation.

Section 4.5.2 is compatible with MSR technology except for terminology and ASME references for high temperature materials.

\subsubsection{Section 4.6, Functional Design of Control Rod Drive System}

The Section 4.6 LWR review text indicates:

The review should confirm that the control rod drive system can provide for a safe shutdown, respond within acceptable limits during AOOs, and prevent or mitigate the consequences of postulated accidents.

Section 4.6 is compatible with MSR technology. Note that MSRs may use control elements other than control rods and intrinsic nuclear phenomena, such as flow, to provide reactor control and safe shutdown. 


\subsubsection{Test Reactor Implications}

Based on the gap analysis of SRP Chapter 4, the following test reactor activities would support the development and NRC review of an MSR prototype SAR:

- Evaluate, verify, and scale decay heat removal mechanisms

- Evaluate fuel system boundary system materials performance

- Evaluate fuel burnup, chemistry control, and fission product control, and verify operating parameters

- Evaluate test, inspection, and surveillance needs

- Extrapolate reactivity-initiated events/data, such as loss of flow or fission-product bubble collapse, to the prototype reactor

- The areas of review make note of analytical methods used, database values/nuclear data libraries, and other nuclear parameters. Develop and prove acceptable analytical methods for the test reactor, including:
o Criticality
o Reactivity coefficients
o Fuel composition (burnup) calculations
o Stability
o Delayed neutron calculations
o Core power distribution

- Collect pressure vessel irradiation data to validate computer codes and to evaluate uncertainties

- Evaluate test reactor anticipated transients without scram response; scale to prototype

- Establish appropriate fuel limits/dose limits/material limits to ensure system integrity

- Establish reactivity coefficient mechanisms and combined values for MSR operation

- Document experiments supporting identification and measurement of MSR nuclear design parameters

- Document experimental data reductions and correlations to verify test reactor thermal and hydraulic phenomena; identify any limiting thermal-hydraulic parameters; scale to prototype

- Provide independent comparisons and correlations of experimental data from various experimental programs

- Examine crud or fission product plate out; evaluate implications for the prototype reactor

- Evaluate component performance in high temperature environment; document high temperature materials testing; support code case development for high temperature materials

- Verify mechanical and systemic shutdown mechanisms

- Generate and validate data for modeling and simulation of MSR transient and accident response

- Establish necessary control element response

Based on a limited review of the references identified for SRP Chapter 4, the following test reactor activities would support the development and NRC review of an MSR prototype SAR:

- Evaluate test reactor source term, generate a source term database; scale to prototype 
- Evaluate test reactor RHR performance; scale to prototype

- Evaluate test reactor control room habitability

- Evaluate off-gas system

- Demonstrate how MSR test reactor operating experience insights can be incorporated into MSR power reactor initial test requirements

- Evaluate blocked channel flow, as applicable

- Document salt test loops and test reactor experience for shutdown and low-power operation

- Document salt test loops and test reactor experience for loss of decay heat removal

- Operate with N-1 fuel salt pumps or fuel salt/coolant loop heat exchangers, as applicable

- Evaluate flow tests in salt loops and the test reactor; scale to prototype

\subsection{SRP CHAPTER 5, "REACTOR COOLANT SYSTEM AND CONNECTED SYSTEMS”}

The focus of the NUREG-0800 Chapter 5 review is to (1) provide assurance that the RCPB will remain intact to supply continuous core heat removal, and (2) evaluate the interaction of interconnected RCPB systems on the ability to provide assurance that the RCPB will remain intact.

\subsubsection{Section 5.2, Reactor Coolant Pressure Boundary}

The Section 5.2 LWR reviews include the following topics as they apply to the RCPB:

- $\quad$ Codes and Standards (5.2.1.1, 5.2.1.2)

- $\quad$ Overpressure Protection (5.2.2)

- $\quad$ Materials (5.2.3)

- $\quad$ Inservice Testing (5.2.4)

- Leak Detection (5.2.5)

The review verifies that acceptable codes and standards (and their edition and addenda) required by 10 CFR 50.55a, “Codes and Standards,” are identified for LWR component construction (5.2.1.1). The review also verifies that acceptable ASME Code Cases are identified for LWR component construction (5.2.1.2). Acceptable Code Cases for construction of LWRs are identified in Regulatory Guide (RG) 1.84 . The listed references and regulations are directed at LWR systems and components. Appropriate ASME Codes and Code Cases are needed to facilitate MSR technology evaluation.

The LWR RCPB overpressure protection review (5.2.2) text indicates:

The overpressure protection system ensures that safety and relief valves and the reactor protection systems provide adequate overpressure protection for the RCPB during operation at power. In addition, the application of pressure-relieving systems that function during low-temperature operation ensure overpressure protection for the RCPB during low-temperature operation of the LWR plant (e.g., startup, shutdown).

The LWR overpressure concern is focused on preventing a catastrophic failure of the RCPB, which could cause a substantial reduction in the capability to maintain reactor coolant inventory and cool the core. This could ultimately lead to a substantial challenge to LWR fuel clad and to the containment, offering a potential for radiological release. This is not the same concern or release progression that would occur in an MSR with multiple barriers, such as a guard vessel as the second barrier. MSRs operate at a low 
pressure and lack mechanisms to generate substantial overpressure. Likewise, the MSR containment would not see the LWR pressure spike challenge caused by steam pressure due to a loss-of-coolant accident (LOCA).

The Section 5.2.3 LWR RCPB materials review "evaluates the specifications for pressure-retaining materials, including weld materials, used for each component (e.g., vessels, piping, pumps, and valves) of the RCPB.” General corrosion and stress corrosion cracking induced by impurities in the reactor coolant, which can cause failures of the LWR RCPB, are reviewed. The MSR review needs to consider a functional containment concept where higher performing materials that lack a full salt-interface pedigree can be employed by the reactor designer in a second or third barrier to release. The system safety function is achieved by providing independent containment layers such as a second barrier system (e.g., guard vessel, guard pipe). All MSR materials need to be evaluated for the independent function that each barrier provides.

Components that are part of the LWR RCPB must be designed to permit periodic inspection and testing of important areas and features to assess their structural and leaktight integrity (5.2.4). Due to the high radiation levels associated with MSR technologies, inspection and testing will need to be done remotely.

The RCPB leakage detection systems (5.2.5) are designed to detect and, to the extent practical, identify the source of reactor coolant leakage.

The specific areas of review for LWRs are:

- Whether the system can identify, to the extent practical, the location of the source of reactor coolant leakage.

- Whether the system can separately monitor and collect leakage from both identifiable and unidentifiable sources.

- Whether the system has adequate indicators and alarms for each leakage detection system in the main control room and readily permits interpretations of indicators related to leak rates.

- Whether the system monitors systems connected to the RCPB for inter-system leakage.

MSRs will also need to detect leaks. Fuel salt leakage will not accumulate in a sump or a tank due to the nature of the fuel salt parameters. Fuel salt leakage will likely be limited, solidify rapidly, and collect in guard systems.

The collective Section 5.2 reviews need to be retained for a review of the MSR fuel salt boundary system. The focus is on the fuel salt boundary system. Note that the fuel is mixed with the coolant in the fuel salt loop. The fuel is discussed in Section 4.2, and the fuel salt system boundary is reviewed in this section.

\subsubsection{Section 5.3, Reactor Vessel}

The current Section 5.3 reviews include the following topics as they apply to the reactor vessel:

- Materials

- $\quad$ Pressure/Temperature Limits

- Integrity

The LWR vessel materials review (5.3.1) text verifies:

The material specifications used for the reactor vessel and applicable attachments and appurtenances, such as the shroud support, studs, control rod drive housings, vessel support skirt, stub tubes, and instrumentation housings, are reviewed and their adequacy 
for use in the construction of such components is assessed on the basis of the mechanical and physical properties of the materials, the effects of irradiation on these materials, their corrosion resistance, and their fabricability.

Manufacturing methods and joining methods are also evaluated. For pool-type MSR technologies, the fuel salt system boundary is the vessel and the primary heat exchanger boundary, which is covered in Section 5.4 (tube or shell wall depending on the design). For loop-type MSRs, there will be a small pipe run from the vessel to the primary heat exchangers. Because MSRs operate at low pressure and do not use heterogeneous fuel, the vessel materials review should be covered by the analyses done in Section 5.2.

The LWR pressure-temperature (P-T) review (5.3.2) evaluates "the P-T limits imposed on the RCPB during any condition of normal operation, including AOOs and hydrostatic tests to ensure adequate safety margins of structural integrity for the ferritic components of the RCPB.” The review also evaluates Charpy upper-shelf energy (USE) values for reactor vessel beltline materials. The review will further evaluate PWR reactor vessel beltline materials to ensure adequate resistance to failure during pressurized thermal shock (PTS) events. P-T limits, USE values, and PTS are used to evaluate the potential for brittle fracture of the LWR (PWR) vessel. As discussed previously, a LOCA does not present the same concern or release progression for an MSR.

LWR RCPB integrity is evaluated in Section 5.3. This summary review evaluates the design, construction materials, fabrication methods, inspection requirements, shipment and installation, operating conditions, in-service surveillance, and operational programs related to the LWR vessel.

The Section 5.3 reviews can be folded into the collective Section 5.2 reviews based on the vessel function differences between typical MSR designs and LWR designs.

\subsubsection{Section 5.4, Reactor Coolant System Component and Subsystem Design}

The Section 5.4 LWR reviews evaluate various components and subsystems within, or associated with, the RCS out to, and including, isolation valves. Most components are LWR-specific. However, new subsections for MSR-specific components and subsystems should be included, such as:

- $\quad$ Residual heat removal (LWR is evaluated in Section 5.4.7)

- Fuel salt pump

- Primary heat exchanger

- Gas management system

- Fuel salt cleanup or polishing system

- Fuel salt makeup system

- Fuel salt sampling system

- Fuel salt drain tank

- Freeze valve boundary

- Connecting piping which might contain fuel salt

\subsubsection{Section 5.5, MSR Coolant Loop Component and Subsystem Design (New)}

The coolant loop components are unique to MSR technology. This primary coolant or nonfuel salt loop transfers heat to the power conversion loop or the ultimate heat sink. Chapter 5 is the most logical SAR chapter in which to include a new section for discussion topics for the primary loop. These topics might include: 
- Coolant loop materials

- Coolant loop chemistry

- Coolant loop cleanup system

- Coolant loop sampling system

- Coolant loop pump

- Coolant heat exchangers

- Coolant loop makeup system

- Coolant loop drain tank

- Coolant loop in-service inspection and testing

- Isolation valves

\subsubsection{Test Reactor Implications}

Based on the gap analysis of SRP Chapter 5, the following test reactor activities would support the development and NRC review of an MSR prototype SAR:

- Support separate but related efforts for needed high temperature codes and standards to establish the minimum quality standards for the design, fabrication, erection, construction, testing, and inspection of prototype/commercial MSR components

- Support separate but related efforts to describe a quality classification system related to specified national standards for MSR technology

- Support separate but related efforts to develop ISI code cases for SSC and supports

- Support separate but related efforts to develop operation and maintenance code cases for power reactor licensing

- Demonstrate how MSR test reactor operating experience insights can be incorporated into MSR power reactor design

- Demonstrate leak detection techniques, provide database on detection; amount, location, etc.

- Provide database of fuel salt boundary pressure for various operating conditions and upsets

- Provide database on performance of boundary coatings and other materials used in the test reactor

- Provide database on fuel salt chemistry control

- Provide lessons-learned on needed ISI and techniques

- $\quad$ Provide database on performance of the fuel salt pump

- Provide database on performance of boundary coatings and other materials used in the test reactor vessel and on heat exchanger materials

- Evaluate MSR subsystems and components associated with the fuel salt system boundary

- Evaluate test reactor RHR performance; scale to prototype

- Evaluate MSR subsystems and components associated with fuel salt clean-up

- Evaluate MSR subsystems and components associated with fuel salt sampling 
- Evaluate off-gas system

Based on a limited review of the references identified for SRP Chapter 5, the following test reactor activities would support the development and NRC review of an MSR prototype SAR:

- Consider and implement code case alternatives necessary to meet 10 CFR 50.55a(z)

- Provide code class input for high temperature, high radiation environment

- Review seismic considerations for the test reactor

- Document high temperature materials testing; provide quality assurance (QA) data on materials performance

- Demonstrate how MSR test reactor fabrication experience insights can be incorporated into MSR design and fabrication code cases

- Demonstrate how MSR test reactor operation and maintenance experience insights can be incorporated into MSR OM code cases

- Demonstrate how MSR test reactor ISI experience insights can be incorporated into MSR ISI code cases

- Demonstrate how MSR test reactor operating experience insights can be incorporated into MSR power reactor initial test requirements

- Feedback lessons learned from the test reactor license application (under NUREG-1537) to the application process for a prototype or commercial reactor

- Apply lessons-learned from the test reactor overpressure protection considerations to the needs of the prototype or commercial MSR

- Provide experience database for low power and shutdown operations

- Provide data for required station blackout response time

- Provide fuel salt boundary system thermal stress data

\subsection{SRP CHAPTER 6, "ENGINEERED SAFETY FEATURES”}

Many of the LWR SRP Sections, and Subsections associated with Chapter 6 do not directly apply to generic MSR technology or require substantial updates.

The focus of the Chapter 6 SRP review is to ensure that plant safety features are provided to mitigate the consequences of design-basis accidents, particularly loss-of-coolant accidents for LWRs, even though the occurrence of these accidents is very unlikely.

\subsubsection{Section 6.1, Materials}

The current Section 6.1 reviews include the following topics as they apply to the RCPB:

- $\quad$ Engineered Safety Features (ESF) Materials (6.1.1)

- $\quad$ Protective Coating Systems (Paints) - Organic Materials (6.1.2)

The LWR ESF material review is based on appropriate ESF material selection for LWRs (6.1.1) and the prevention of a catastrophic failure of the RCPB. The Review and Evaluation Findings are based on identifying materials that are compatible with the chemically controlled primary coolant water. 
Additionally, the types and quantities of radiation and chemical decomposition products that can be produced from all the paints and organic materials which are exposed to the containment atmosphere are reviewed (6.1.2). The stability of materials including protective coatings and organics are examined to determine the potential formation of decomposition products under design basis accident conditions.

MSRs have ESF systems that are different from LWRs and operate in a different temperature, pressure, chemical, and radiation environment. Discussion for MSRs should identify the function of each boundary layer and the associated material requirements.

\subsubsection{Section 6.2, Containment}

The LWR containment reviews include the following topics as they apply to a traditional containment structure:

- $\quad$ Containment Functional Design (6.2.1 and 6.2.1.1A, 6.2.1.1.B, 6.2.1.1.C)

- Containment Heat Removal Systems (6.2.2)

- Secondary Containment Functional Design (6.2.3)

- Containment Isolation System (6.2.4)

- Combustible Gas Control in Containment (6.2.5)

- Containment Leakage Testing (6.2.6)

- Fracture Prevention of Containment Pressure Boundary (6.2.7)

The LWR containment functional design review (6.2.1) verifies:

The containment structure is capable of withstanding, without loss of function, the pressure and temperature conditions resulting from postulated LOCA, steam line, or feedwater line break accidents.

Specific PWR and BWR containment requirements are discussed in the containment function subsections. The principle regulatory basis for the review is 10 CFR 50, Appendix K, ECCS Evaluation Models. Appendix K assumes an emergency core cooling system response to a LOCA and protection for heterogeneous fuel.

The LWR containment heat removal system review (6.2.2) evaluates containment heat removal. The emphasis is on post-LOCA cooling for LWRs. The discussion needs to be tailored for MSR technology, identified MSR LBEs and any subsequent containment heat removal issues. Similar considerations need to be made for review of any applicable secondary containment (6.2.3)

The LWR containment isolation system review (6.2.4) indicates:

The containment isolation system should allow for the normal or emergency passage of fluids through the containment boundary while preserving the ability of the boundary to prevent or limit the escape of fission products from postulated accidents.

This philosophy is applicable to MSRs, though the discussion topics include LOCAs and containment purge. Identified MSR LBEs need to be considered.

It is noted in Section 6.2.5 that guidance for control of combustible gas in containment may be found in Regulatory Guide (RG) 1.7, Control of Combustible Gas Concentrations in Containment, including nonLWRs. RG 1.7 specifically notes that non-LWR applicants should provide information addressing whether accidents involving combustible gases are technically relevant for their design. An MSR applicant will need to provide a justification stating why this section is not applicable. In general, except for the potential for boundary coatings and organic materials exposed to the containment atmosphere to 
release combustible gases, accidents involving combustible gases are not technically relevant for MSRs. The LWR review of combustible gas control in containment deals with fuel clad-coolant reaction between the fuel cladding and the reactor coolant and molten core-concrete interaction in a severe heterogeneous fuel core melt sequence with a failed reactor vessel. These are LWR-specific issues.

LWR SRP Section 6.2.6, “Containment Leakage Testing,” is applicable to MSRs without significant changes. LWR SRP Section 6.2.7, "Fracture Prevention of Containment Pressure Boundary," is not expected to be applicable to MSRs because, unless water is present in a containment system, there is no identified containment pressurization source.

Essentially, containment functional design requirements need to be developed for generic MSR technologies. Additional containment review requirements will then be developed from that basis.

\subsubsection{Section 6.3, Emergency Core Cooling System}

The LWR Emergency Core Cooling System (ECCS) review (6.3) text indicates:

Sufficient ECCS capacity is necessary to assure that specified acceptable fuel design limits and the design conditions of the reactor coolant pressure boundary are not exceeded during AOOs and that the core is cooled during accident conditions. The ECCS should provide an abundance of core cooling to transfer heat from the core at a rate so that fuel and clad damage will not interfere with continued effective core cooling.

This is directly applicable to LWRs with heterogeneous fuel. The concern for MSRs is the integrity of the fuel salt system boundary. For passively safe MSRs, the ECCS function is accomplished by a passive RHR system which may also serve as the containment or reactor building passive cooling system. Thus, some MSRs may not have a separate, dedicated ECCS.

\subsubsection{Section 6.4, Control Room Habitability System}

The LWR control room habitability system review (6.4) text includes some parameters that are specific to LWRs. However, this section is largely applicable to MSRs as written.

\subsubsection{Section 6.5, Containment Support Systems}

The LWR containment support system reviews include the following topics as they apply to traditional containment support systems:

- $\quad$ ESF Atmosphere Cleanup Systems (6.5.1)

- Containment Spray as a Fission Product Cleanup System (6.5.2)

- Fission Product Control Systems and Structures (6.5.3)

- Ice Condenser as a Fission Product Cleanup System (6.5.4)

- Pressure Suppression Pool as a Fission Product Cleanup System (6.5.5)

The LWR atmosphere cleanup systems review (6.5.1) text includes review of atmosphere cleanup systems designed for fission product removal in post-accident environments. The review assumes air ventilation and includes review of heaters, demisters, pre-filters, and high-efficiency particulate air filters, design requirements of the filter and adsorber mounting frames, system filter and adsorber housings, and water drains, the adsorbent used for removal of gaseous iodines, the physical properties of the adsorbent, and the design of the adsorber section of the filter trains. MSRs will likely inert containment and appropriate cleanup systems for a given design will need to be discussed.

The LWR fission product control SSC review (6.5.3) text indicates: 
The fission product control systems and structures are reviewed to (a) provide a basis for developing the mathematical model for design basis LOCA dose computations, (b) verify that the values of certain key parameters are within pre-established limits, (c) confirm the applicability of important modeling assumptions, and (d) verify the functional capability of ventilation systems used to control fission product release. The parameters that must be established for use in the calculation of the radiological consequences of accidents in Chapter 15 of the safety evaluation report are evaluated.

RG 1.52 provides guidance for LWR atmospheric cleanup systems. MSRs operate at a low pressure and lack mechanisms to generate substantial overpressure. The source terms will differ for MSR technology, which will, in part, dictate appropriate containment leakage rate limits.

Subsections on containment spray (6.5.2), ice condensers (6.5.4), and suppression pools (6.5.5) do not apply to MSR technologies.

\subsubsection{Section 6.6, Inservice Inspection and Testing of Class 2 and 3 Components}

The LWR in-service inspection review text indicates:

Inservice inspection (ISI) programs are based on the requirements of 10 CFR 50.55a, which requires that Code Class components meet the applicable inspection requirements set forth in Section XI, "Rules for Inservice Inspection of Nuclear Power Plant Components," of the ASME Boiler and Pressure Vessel Code.

While ISI is applicable to MSR technologies, high temperature codes and standards need to be developed further for MSR designs. In addition, conducting component ISI in a high temperature, high radiation environment will need to be addressed by the MSR review.

\subsubsection{Section 6.7, Main Steam Isolation Valve Leakage Control System (BWR)}

Direct cycle boiling water reactor BWR plants have redundant quick-acting isolation valves on each main steam line from the reactor to the turbine. In the event of a LOCA, any leakage of contaminated steam through these valves is controlled by a leakage control system. This section does not apply to MSR technologies.

\subsubsection{Test Reactor Implications}

Based on the gap analysis of SRP Chapter 6, the following test reactor activities would support the development and NRC review of an MSR prototype SAR:

- Provide QA database on performance of materials used in the test reactor containment and ESF SSC

- Provide QA database on performance of boundary coatings and organic materials used in the test reactor containment

- Provide insight on appropriate system interfaces

- Evaluate and scale test reactor containment parameters

- Provide containment performance data, including heat removal

- Evaluate gas content, pressures and temperatures in containment

- Analyze subcompartment parameters, if applicable, in the test reactor

- Compare containment experimental data and recognized correlations, if applicable 
- Identify any energy sources that are available for release to the containment

- Identify any primary cooling loop energy sources that are available for release to the containment

- Support testing of containment isolation methods, if applicable

- Verify appropriate containment leakage rate for MSRs; provide leakage rate and dose data

- Provide operational data for test reactor systems providing an ECCS function; evaluate the need for ECCS components for the prototype reactor

- Provide data and experience with ESF containment atmosphere cleanup system used for test reactor

- Provide data and experience with fission product control SSC used for test reactor

- Support separate but related efforts for needed high temperature codes and standards to establish the minimum quality standards for the design, fabrication, erection, construction, testing, and inspection of prototype/commercial MSR components

Based on a limited review of the references identified for SRP Chapter 6, the following test reactor activities would support the development and NRC review of an MSR prototype SAR:

- Consider and implement Code Case alternatives necessary to meet 10 CFR 50.55a(z)

- Provide database of any combustible gas concentrations in containment

- Demonstrate how MSR test reactor fabrication experience insights can be incorporated into MSR design and fabrication code cases

- Demonstrate how MSR test reactor operating experience insights can be incorporated into MSR power reactor initial test requirements

- Provide QA data on environmental performance of electrical equipment; establish environmental qualification process for prototype

- Provide data on in-plant testing of valves such as freeze valves

- Provide experience database for low power and shutdown operations

- Provide code class input for high temperature, high radiation environment

- Review seismic considerations for the test reactor

- Establish design, testing, maintenance criteria for MSR containment atmosphere systems

- Establish test methods and requirements for plant upset monitoring

- Provide data for required station blackout response time

- Provide confirmatory measured radiation levels

- Support separate but related efforts to develop ISI Code Cases for SSC and supports

- Provide confirmatory data for LBE transient modeling and simulation codes

- Provide net positive suction head data for MSR pumps, as applicable

- Provide heat trace data and other line-warming techniques to avoid unintended salt freeze

- Provide QA performance data for the test reactor control room habitability system 


\subsection{SRP CHAPTER 9, “AUXILIARY SYSTEMS”}

The LWR SRP Chapter 9 review evaluates individual LWR auxiliary support systems that are safetyrelated or that are important to safety, including cooling systems, diesel systems, fuel handling, and fuel storage systems. Chapter 9 offers many areas where the test reactor can provide extensive experience, data, and insight for a commercial MSR application. Those auxiliary systems that are not LWR-specific potentially apply to MSRs. In addition, there are numerous additional support systems, specific to MSR applications, that should be included in Chapter 9 .

\subsubsection{Section 9.1, Fuel Handling and Storage}

The LWR fuel handling and storage reviews include the following fuel handling topics:

- Criticality Safety of Fresh and Spent Fuel Storage and Handling (9.1.1)

- $\quad$ New and Spent Fuel Storage (9.1.2)

- $\quad$ Spent Fuel Pool Cooling and Cleanup System (9.1.3)

- $\quad$ Light Load Handling System (9.1.4)

- $\quad$ Overhead Heavy Load Handling Systems (9.1.5)

The LWR fresh and spent fuel storage and handling review (9.1.1) is based on handling and protection of heterogeneous fuel assemblies, including the spent fuel pool and fuel assembly storage racks (9.1.2). Criticality safety and fuel storage will require substantial modification for consideration of MSR homogenous fuel.

The LWR spent fuel pool cooling and cleanup system (9.1.3) is not applicable to MSR liquid fuel. The light load handling system (9.1.4) is focused on fuel assembly receipt and reactor refueling activities. This system is not applicable to MSRs with homogenous fuel; however, a fuel salt handling system will need to be considered for fuel receipts and shipments. The LWR heavy load handling system (9.1.5) is generally applicable to MSRs because a failure of the heavy load system could damage the plant in general.

New auxiliary subsections for MSR-specific fuel handling and storage should be included, such as:

- Fuel Salt Load Handling System

- Fuel Accountability System (safeguards)

\subsubsection{Section 9.2, Cooling Fluids}

The LWR cooling fluid reviews include the following cooling system topics:

- $\quad$ Station Service Water System (9.2.1)

- Reactor Auxiliary Cooling Water System (9.2.2)

- Demineralized Water Makeup System (9.2.3) [Withdrawn]

- Potable and Sanitary Water System (9.2.4)

- Ultimate Heat Sink (9.2.5)

- $\quad$ Condensate Storage Facilities (9.2.6)

- $\quad$ Chilled Water Systems (9.2.7)

The LWR review is based on cooling water and other water-based systems for plant systems. 
The LWR service water system (9.2.1) provides essential cooling to safety-related equipment and may also cool nonsafety-related auxiliary components for normal plant operation. It is unlikely that water as a cooling fluid will be used in an MSR; therefore, the service water system will not be applicable to MSRs as a safety system or an important-to-safety system. An MSR test reactor will provide the opportunity to evaluate alternate cooling fluids and systems for safety-related equipment.

The LWR auxiliary cooling water system (9.2.2) provides a closed loop of cooling water for reactor system components, reactor shutdown equipment, ventilation equipment, and components of the emergency core cooling system (6.3). This system is LWR-specific and is not applicable to MSRs because MSRs will avoid the use of water inside containment to avoid a steam pressurization source from interacting with high temperature fuel salt. A new review section for reactor component cooling is needed for non-water-cooling systems that are safety-related or important to safety.

The potable and sanitary water system (9.2.4) is technology-neutral and is applicable to MSRs. Likewise, the ultimate heat sink (9.2.5) discussion is technology-neutral and is applicable to MSRs. In addition to water cooling, the ultimate heat sink section includes discussion of air cooling and hybrid cooling.

The LWR condensate storage facilities (CSFs) (9.2.6) will likely not be safety-related for an MSR application. LWRs rely on the CSFs to support decay heat removal (typically through the auxiliary feedwater system). MSRs will not rely on a water-based system. MSRs may use CSFs to support the power conversion system. However, this will support normal operations and plant equipment protection. AOOs and accidents will not rely on the CSFs for protection. Section 9.2.6 will support a review of a non-safety-related MSR CSF.

The chilled water system (9.2.7) provides a closed loop of cooling water for room ventilation equipment and components of the emergency core cooling system. In addition, the system may also provide cooling to non-safety-related components such as miscellaneous pumps and ventilation equipment. Any MSR chilled water systems are expected only for non-safety-related components. The test reactor will provide experience and insight on necessary chilled water systems.

New auxiliary subsections for MSR-specific cooling fluids should be included, such as:

- Reactor Auxiliary Cooling Fluid System

- Fuel Salt Storage Cooling Fluid System

- Gas Management System Cooling

- Fuel Salt Drain Tank Cooling System

- Primary Coolant Drain Tank Cooling System

\subsubsection{Section 9.3, Air, Sampling, and Drain Systems}

The LWR air, sampling, and drain system reviews include the following miscellaneous support system topics:

- $\quad$ Compressed Air System (9.3.1)

- $\quad$ Process and Post-accident Sampling System (9.3.2)

- Equipment and Floor Drainage System (9.3.3)

- Chemical and Volume Control System (PWR) (9.3.4)

- $\quad$ Standby Liquid Control System (BWR) (9.3.5) 
The compressed air system (9.3.1) is essentially applicable to MSRs as written. There are numerous LWR-specific examples used that could be made neutral. An MSR test reactor will provide the opportunity to evaluate compressed air systems for safety-related equipment.

The process and post-accident sampling system (9.3.2) is a necessary consideration for MSRs. The current section is LWR-focused. There is a need to define MSR sampling requirements to ensure that regulatory conditions are met. A new fuel salt sampling system subsection is recommended in Section 5.4.

The focus of the equipment and floor drainage system (9.3.3) is on liquid systems outside containment. This will likely be limited in application. An MSR test reactor could provide the opportunity to evaluate drainage systems.

Subsections 9.3.4 and 9.3.5 are LWR-specific. However, the combined function of the chemical and volume control system proposed for MSRs requires a new gas management system subsection (5.4.16), a new fuel salt cleanup or polishing system subsection (5.4.17), and a new fuel salt makeup system subsection (5.4.18).

New auxiliary subsections for MSR support should be included, such as:

- MSR Fuel Salt Heating System

- MSR Cover Gas Cleanup and Purification System

\subsubsection{Section 9.4, Ventilation Systems}

The LWR ventilation system reviews include the following topics:

- Control Room Area Ventilation System (9.4.1)

- $\quad$ Spent Fuel Pool Area Ventilation System (9.4.2)

- Auxiliary and Radwaste Area Ventilation System (9.4.3)

- $\quad$ Turbine Area Ventilation System (9.4.4)

- Engineered Safety Feature Ventilation System (9.4.5)

The control room area ventilation system (9.4.1) provides a controlled environment for the comfort and safety of control room personnel and ensures the operability of control room components during normal operation, AOOs, and design-basis accident conditions. The subsection is applicable to MSRs, although the current guidance documents related to source term may not be adequate. Experience with the test reactor control room ventilation system will provide QA performance data.

A ventilation system for the LWR spent fuel pool (9.4.2) is not applicable to MSRs; however, some guidance will be necessary for any safety-related ventilation system necessary for MSR fuel salt storage (new and used). Experience with the test reactor fuel storage ventilation system will provide QA performance data.

The auxiliary and radwaste area ventilation system (9.4.3) maintains ventilation, permits personnel access, and controls the concentration of airborne radioactive material in the auxiliary and radwaste equipment areas during normal operation, AOOs, and after postulated accidents. As in subsection 9.4.1, the current guidance documents related to source term may not be adequate. Experience with the test reactor radwaste ventilation system will provide QA performance data.

The turbine area ventilation system (9.4.4) maintains ventilation, permits personnel access, and controls the concentration of airborne radioactive material in the turbine area during normal operation, AOOs, and 
after any accident that results in a release of radioactive material. As in subsection 9.4.1, the current guidance documents related to source term may not be adequate.

The engineered safety feature ventilation system (9.4.5) provides a suitable and controlled environment for engineered safety feature components (6.3) following certain anticipated transients and design-basis accidents. Certain MSR designs may not require any ESF components. As in subsection 9.4.1, the current guidance documents related to source term may not be adequate.

New auxiliary subsections for MSR support could be included, such as:

- $\quad$ MSR Fuel Salt Storage Ventilation System

\subsubsection{Section 9.5, Fire, Communications, Lighting, and Diesel Support Systems}

The fire, communications, lighting, and diesel support system reviews include the following system and program topics:

- Fire Protection Program (9.5.1.1)

- $\quad$ Risk-Informed, Performance-Based Fire Protection Program (9.5.1.2)

- Communications Systems (9.5.2)

- $\quad$ Lighting Systems (9.5.3)

- Emergency Diesel Engine Fuel Oil Storage and Transfer System (9.5.4)

- Emergency Diesel Engine Cooling Water System (9.5.5)

- $\quad$ Emergency Diesel Engine Starting System (9.5.6)

- Emergency Diesel Engine Lubrication System (9.5.7)

- Emergency Diesel Engine Combustion Air Intake and Exhaust System (9.5.8)

Subsection 9.5.1.1 addresses the traditional deterministic approach to fire protection. This section is applicable for MSR applicants opting to incorporate a deterministic approach to their Fire Protection Program (FPP). This section, along with National Fire Protection Association (NFPA) 804, has been used in design certification and combined license applications. The FPP experience at the MSR test reactor should be incorporated into review.

License amendment requests to transition to a risk-informed, performance-based FPP approach are addressed in SRP section 9.5.1.2. This SRP section is based on NFPA 805. The scope of NFPA 805 is stated as providing minimum fire protection requirements for existing light water nuclear power plants.

The communication systems (9.5.2) and the lighting systems (9.5.3) are technology-neutral. Experience with the comparable test reactor systems will provide QA performance data.

MSRs are anticipated to be passively safe designs. The extent to which any MSR design may rely on emergency diesel generators and their support systems (9.5.4 through 9.5.8) is not currently known. However, it is likely that any MSR diesel generators will simply be provided as auxiliary power supplies.

No new auxiliary subsections are recommended for Subsection 9.5.

\subsubsection{Test Reactor Implications}

Based on the gap analysis of SRP Chapter 9, the following test reactor activities would support the development and NRC review of an MSR prototype SAR: 
- Demonstrate how MSR test reactor operating experience insights can be incorporated into MSR power reactor design to address criticality safety

- Demonstrate how MSR test reactor operating experience insights can be incorporated into MSR power reactor design to address new and used fuel storage issues

- Review new and used fuel storage load handling for the test reactor

- Evaluate cooling systems for test reactor essential components

- Evaluate the test reactor ultimate heat sink; scale to prototype

- Evaluate the test reactor equivalent to LWR “chilled water” systems; scale cooling systems to prototype

- Evaluate the test reactor compressed air system experience

- Evaluate the test reactor sampling systems

- Evaluate the test reactor drain systems

- Evaluate off-gas system

- Evaluate test reactor control room ventilation system

- Evaluate test reactor fuel salt storage ventilation system

- Evaluate test reactor radwaste storage ventilation system

- Evaluate other test reactor ESF ventilation systems

- Evaluate test reactor fire protection systems and fire protection program

- Evaluate fuel salt heating components used at MSR test reactor

- Evaluate cover gas cleanup and purification experience at MSR test reactor

Based on a limited review of the references identified for SRP Chapter 9, the following test reactor activities would support the development and NRC review of an MSR prototype SAR:

- Evaluate radiation protection program at test reactor

- Evaluate radwaste program at test reactor

- Provide code class input for high temperature, high radiation environment

- Review seismic considerations for the test reactor

- Establish design, testing, and maintenance criteria for MSR containment atmosphere systems

- Evaluate occupational exposure at the test reactor; evaluate programs to limit worker dose; scale to prototype

- Evaluate blackout coping capability of the test reactor; scale to commercial reactor

- Review maintenance performed at MSR test reactor

- Demonstrate how MSR test reactor operating experience insights can be incorporated into MSR power reactor initial test requirements

- Feedback lessons learned from the test reactor license application (under NUREG-1537) to the application process for a prototype or commercial reactor

- Establish test methods and requirements for plant upset monitoring 
- Provide lessons learned on needed ISI and techniques

- Provide QA performance data for the test reactor control room habitability system

- $\quad$ Evaluate test reactor man-machine interfaces

\subsection{SRP CHAPTER 11, “RADIOACTIVE WASTE MANAGEMENT”}

LWR SRP Chapter 11 is generally applicable to MSRs in all areas, although a liquid waste management system may not apply in the same way that it does for a LWR. Ultimately, the test reactor can potentially provide a wealth of information to help fill many of the identified gaps.

The NUREG-0800 Chapter 11 review evaluates plant waste management.

\subsubsection{Section 11.1, Coolant Source Terms}

The LWR coolant source term text indicates that the normal operational coolant source term and the AOO coolant source term must be evaluated so that appropriate waste system design features to process, treat, release, or recycle liquid and gaseous effluents can be developed. The design features will include ventilation, shielding, and monitoring. The source term analysis is based on small defects in the heterogeneous fuel (less than 1\%).

The design basis source term represents a conservative characterization of primary and secondary coolant concentrations. The source term is based on a combination of assumptions of failed fuel fractions, TS limits for halogens (I-131 dose equivalent) and noble gases (Xe-133 dose equivalent), presence of activation and corrosion products, and steam generator TS limits on primary-to-secondary leakage.

In an MSR, there is no mechanical structure for the fuel. The fuel salt source term will include actinides and fission products from operation. Some fission products will accumulate in a gaseous form. After accumulating in an off-gas system, some of the initial gaseous fission products could change state or decay back to a liquid or solid, while others remain in gaseous form. Other fission products will be soluble and build up in the fuel salt. The remaining fission products, typically noble metals, are insoluble and may accumulate or concentrate in various regions of the core or vessel. Therefore, the MSR source term will not resemble the LWR source term. Likewise, the typical leakage paths will differ, such that offsite dose calculations will not be the same for the two reactor types. Subsequent MSR waste design features will need to consider the unique MSR operating parameters.

Section 11.1 needs to be retained for a review of MSR coolant source terms, but it needs an extensive rewrite. In addition, the supporting calculational tools for the review are generally LWR-specific.

\subsubsection{Section 11.2, Liquid Waste Management System}

The LWR liquid waste management system (LWMS) review text indicates that the system used to manage and treat process and effluent streams must be evaluated to demonstrate compliance with regulatory limits on liquid effluent discharges and associated doses to members of the public.

In LWRs, the LWMS is designed to ensure that liquids and liquid wastes produced during normal operation, including AOOs, are handled, processed, stored, and released or routed to their final destination in accordance with the relevant NRC regulations. The review of the LWMS includes design features that are necessary for collecting, handling, processing, treating, releasing, storing, and disposing of liquid effluents.

This review encompasses, but is not limited to tanks, piping, pumps, valves, filters, demineralizers, mobile equipment connected to permanently installed systems, and any 
additional equipment that may be necessary to process and treat liquid wastes and route them to the point of discharge from the system.

In an MSR, the fuel salt will likely be retained onsite for reuse. Cleanup or polishing systems may be used on the fuel salt to limit fission product poison buildup, but this is not expected to generate liquid waste. The fuel salt system boundary will likely be backed by a guard pipe system. Any fuel salt that leaks into the cooler guard pipe region will solidify, and further leakage beyond a functional containment in liquid form is unlikely. Water-based cooling systems will likely not be included inside containment to avoid the potential for a steam-driven pressure spike following an SSC failure. A steam cycle may be used in an MSR as the power conversion system in a tertiary loop. Contamination of this loop may be determined to be unlikely. Release of treated or decayed fuel salt or coolant to the environment is not an MSR design objective. Therefore, a LWMS may not be needed in an MSR design. However, cleanup of removed components or laundry may necessitate a LWMS.

Section 11.2 needs to be retained for a review of individual MSR technologies, but it may not be applicable to most MSR designs.

\subsubsection{Section 11.3, Gaseous Waste Management System}

The LWR gaseous waste management system (GWMS) review text indicates that the system used to manage and treat process and effluent streams must be evaluated to demonstrate compliance with regulatory limits on gaseous effluent discharges and associated doses to members of the public.

In LWRs, the GWMS is designed to ensure that gaseous wastes produced during normal operation, including AOOs, are handled, processed, stored, and released or routed to their final destination in accordance with the relevant NRC regulations. The GWMS provides for the management of radioactive gases generated by the offgas system, which includes waste gas storage tanks, waste gas decay tanks, and charcoal delay beds, depending on the type of plant and design features. The GWMS has been categorized as nonsafetyrelated and nonrisk-significant.

The MSR GWMS will play an important role in plant operation due to the generation and removal of gaseous fission products in the fuel salt. The MSR GWMS will be a safety-related system. The MSR GWMS will need to be inside a containment structure to protect workers and the public from exposure to the fission product gases associated with high radiation dose and from the potential for actinide carryover into the system.

Section 11.3 needs to be retained for a review of the MSR GWMS, but it will require rewrite and development of supporting documentation and codes for calculation and modeling.

\subsubsection{Section 11.4, Solid Waste Management System}

The LWR solid waste management system (SWMS) review text indicates that the system used to manage and treat process and effluent streams must be evaluated to demonstrate compliance with regulatory limits on solid effluent discharges and associated doses to members of the public.

In LWRs, the SWMS manages radioactive wastes, as liquid, wet, and dry solid wastes, produced during normal operation and AOOs. Review of the SWMS includes design features that are necessary for collecting, handling, processing, and storing wastes in facilities that are part of the nuclear island (e.g., radioactive waste building) or in other buildings (e.g., as a detached radioactive waste storage only facility). The review encompasses, but is not limited to the design, design objectives, design criteria, treatment methods, and expected releases, including the description of the SWMS, mobile equipment connected to permanently installed systems, piping and instrumentation 
diagrams, process and effluent radiation monitoring and control instrumentation, and process flow diagrams showing the operational methods and factors that influence waste treatment. The review includes an evaluation of any additional equipment that may be necessary to process liquid, dry, and wet wastes and route them to the point of discharge from the SWMS or to prepare them for shipment to authorized offsite disposal sites or licensed radioactive waste processors.

The review of the MSR SWMS will be similar to the review of an LWR SWMS. Although dewatering solid waste will not apply at MSRs, most of the remaining Section 11.4 discussion will be applicable to MSRs as written. However, solid waste from an MSR will be much hotter than solid wastes from LWRs.

\subsubsection{Section 11.5, Process and Effluent Radiological Monitoring Instrumentation and Sampling Systems}

The LWR process and effluent radiological monitoring instrumentation and sampling system (PERMISS) review text indicates that the system used to control, monitor, and sample process and effluent streams before being treated and released from LWRs must be evaluated to demonstrate compliance with regulatory limits on radioactive effluent discharges and associated doses to members of the public.

In LWRs the PERMISS is used to monitor liquid and gaseous process streams and effluents from the LWMS, GWMS, and SWMS. The PERMISS includes systems used to collect process and effluent samples during normal operation, AOOs, and under accident and post-accident conditions.

Typically, radiation monitoring systems consist of one or more remote monitors; a centrally located cabinet or console where data from radiation detectors are received, recorded, converted to meaningful radiological units, and displayed in the control room. Other hardware includes necessary interconnecting cables, power supplies, actuators and motors, sampling pumps, alarms, recorders, display panels, and other auxiliary components. Some monitoring systems designs rely on the placement of a radiation detector near or within the effluent streams in achieving the same function without diverting any portion of the effluent stream. In specific applications, radiation monitoring systems are used to automatically initiate a protective action when exceeding a defined instrumentation alarm set-point, such as in terminating or diverting a process stream or effluent releases.

An MSR PERMISS will play a similar radioactive waste management role as that performed for LWRs. Some rewrite of Section 11.5 will be required for development of supporting documentation and codes for calculation and modeling.

\subsubsection{Test Reactor Implications}

Based on the gap analysis of SRP Chapter 11, the following test reactor activities would support the development and NRC review of an MSR prototype SAR:

- Evaluate test reactor source term; generate a source term database; scale to prototype

- Determine if an LWMS is required for an MSR

- Evaluate GWMS performance in the test reactor operation; scale to prototype

- Evaluate SWMS performance in the test reactor operation; scale to prototype

- Evaluate PERMISS performance in the test reactor operation; scale to prototype 
- Evaluate releases from test reactor; evaluate release codes used for review; use experimental data to validate MSR release codes and develop guidance; scale to prototype

Based on a limited review of the references identified for SRP Chapter 11, the following test reactor activities would support the development and NRC review of an MSR prototype SAR:

- Evaluate radiation guidelines; evaluate radiation protection program; scale to prototype

- Evaluate test reactor fire protection program

- Review maintenance performed at MSR test reactor

- Evaluate test reactor control room layout and function

- Evaluate radwaste program at test reactor

- Evaluate all waste sampling programs

- Evaluate test reactor waste disposal packaging, and waste handling and shipping; scale to prototype

- Evaluate operation of waste storage tanks

- Evaluate operation of ventilation filters

- Evaluate air and gas effluent monitoring

- Evaluate offgas sampling

- $\quad$ Evaluate ventilation HEPA filters

- Evaluate protection against groundwater contamination

- Evaluate offsite dose calculations/scaling

- Evaluate test reactor leak monitoring and response

- Establish design, testing, and maintenance criteria for test reactor containment atmosphere systems

- Provide QA data on materials performance

- Demonstrate how MSR test reactor operating experience insights can be incorporated into MSR power reactor initial test requirements

- Establish test methods and requirements for plant upset monitoring

- Feedback lessons learned from the test reactor license application (under NUREG-1537) to the application process for a prototype or commercial reactor

- Document test reactor experience with instruments for MSR effluent monitoring

- Evaluate test reactor process control program

- Evaluate programs to minimize contamination 


\section{FUTURE WORK}

Future work could include expanding the gap analysis to other NUREG-0800 chapters as appropriate. In addition, development of draft technology-neutral text for a standard review plan for MSRs may be appropriate. Future work on developing a licensing approach for MSRs would include working with developers and the NRC to generate separate effects and integrated effects tests to inform the regulatory bases of MSRs. There will also be a need to support and inform the discussion of policy issues such as use of functional containment, use of mechanistic source terms, more reliance on performance-based and risk-informed regulatory processes to select licensing basis events (LBEs), safety categorization of structures, systems, and components (SSCs), and well-defined defense-in-depth systems. Stakeholder feedback will be necessary as the NRC prepares and circulates MSR guidance. 